\title{
Estimation of Forest Carbon Absorption by Forest Stands - Comparison of Two Approaches of Measurement: Manual Field Survey versus Using a Terrestrial LiDAR
}

\author{
LEE Chan-Jung ${ }^{1}$, YOUN Yeo-Chang,"*
}

\author{
${ }^{1}$ Institute for Human-nature Coexistence, Seoul, South Korea \\ ${ }^{2}$ Institute for Human-nature Coexistence, Seoul School of Integrated Science and Technology, Seoul, South \\ Korea \\ ${ }^{*}$ Corresponding author. Email: youn@snu.ac.kr
}

\begin{abstract}
The carbon market is growing in quantitative and qualitative ways as climate change becomes a reality. Particularly, forests are recognized as carbon sink by the United Nations, and its role is drawing more attention as a cost-effective way of mitigating climate change. In Korea, the forest carbon offset scheme is defined as a system in which companies, forest owners, and local governments voluntarily maintain and promote carbon sinks, and the government certifies the amount of forest carbon absorption through it. The purpose of this study is to identify the difference in terms of forest carbon stock when measured using on-the-ground manual methods and digital techniques using terrestrial Lidar on a large area. The study results show that the two methods are not different.
\end{abstract}

Keywords: forest carbon accounting, forest inventory, ground survey, LiDAR.

\section{INTRODUCTION}

The Climate change or global warming represents a rise in air temperatures around the world's oceans and near the surface that began in the late 19th century [1]. Under the Paris Agreement in 2015, nations agreed to keep warming "well under $2.0^{\circ} \mathrm{C}$ " by reducing greenhouse gas (GHG) emissions [2]. As climate change becomes a reality, efforts to reduce greenhouse gas emissions are active in many countries. Through the Kyoto Protocol and the Paris Agreement, the emission trading system using the carbon market is emerging as an effective means of reducing greenhouse gases [3].

Forests are recognized as carbon sink by the United Nations, and its role is drawing more attention as a cost-effective way of mitigating climate change [4]. The United Nations Framework Convention on Climate Change (UNFCCC) defines "carbon sinks" as processes, activities, or mechanisms that remove carbon dioxide from the atmosphere [5].
In South Korea, the forest carbon scheme can be defined as a system in which companies, forest owners, and local governments voluntarily maintain and promote carbon sinks, and the government certifies the amount of forest carbon absorption secured through it [6]. Korea Forest Service (KFS) enacted in 2013 the "Act on the Maintenance and Promotion of Carbon Sink" to provide legal grounds in order to allow voluntary market transactions of forest carbon absorption [7]. Carbon absorption can be certified in managing the carbon sinks by creating and managing forests, using wood products, or using forest biomass energy such as pellets [7].

According to the National Atlas of Korea (2019), mountains cover 70 percent of Korean Peninsula and arable plains are generally small and fall between the successive mountain ranges [8]. The peninsula becomes more mountainous towards the north and the east, with the highest mountains (including Baekdu Mountain which stands at 2,744 meter) found in the north [8]. The average altitude of the Korean Peninsula is about 448 meters, which is very small 
compared to the overall average of 910 meters in East Asia [8].

KFS analysed forest's function of public benefit in Korea, its economic effect is as follows; The forests provide public benefits worth of 221 trillion KRW (About 9\% of the GDP) [9]. The benefit for GHG absorption and sequestration is worth 75.6 trillion KRW (Primary function). The forests absorb $10.3 \%$ of total GHG emission and each year, 2.16 million $\mathrm{KRW}$ of forest welfare benefit is provided per each citizen [9].

Korean Forest Carbon Center provides forest carbon inventory guidelines for forest carbon offset project, when following this guideline, the survey ratio of the sample area shall be at least $1 \%$ of the area of each section of the project site [10]. A cluster plot can be chosen from several forms, and the length or radius of the cluster plot may vary depending on its shape. The area of one sample plot is at least 0.04 ha [10].

The growth information of standing trees, biomass (dry weight), and forestry units are important factors in forest management, and the use of high accuracy and various kinds of yield tables are essential. The Forestry Bureau in many developed countries uses a list of dozens of preferred species in each country. Currently, Korea uses the 'growth and yield table' provided by the National Institute of Forest Science $(\mathrm{NiFoS})$ to grasp the information on the growing stock of trees and weights $[11 ; 12]$.

The first objective of this study is to identify whether there is difference in terms of forest carbon stock when measured using traditional on-the-ground survey methods and techniques using Lidar on a large area. The second objective is to predict the annual growth of each species, stratified by species, and applied with an allometric estimation.

\section{MATERIALS AND METHODS}

\subsection{Study area and data sources}

Study area is Baegunsan Mountain, which is located in Gwangyang City and its vicinity in Jeollanam-do (far south of Korea). Most of Baegunsan area is managed by Seoul National University as research forest. In this research, a total area of 7968.68ha was selected.

Forest Management Plan (FMP) record, boundary map, digital stock map (species-based), and compartment map were referred and combined to GIS digital file. The FMP of research forest had been established in 1957, and the first and second plans were made on a 10-year basis and the third to sixth on a five-year basis, to date, the plan has been drawn up on a 10-year basis again $[13 ; 14]$. In the research, we used 8th Forest Management Plan description and record $[13 ; 14]$.

\subsection{Field measurement equipment}

The field survey equipment is divided into two types according to the survey method. The first method is the traditional manual method, which equipment includes distance measurement, caliper, height meter, laser vertex, clinometer, increment borers, compass, GPS, counter, etc [15]. The second method is Lidar method, which equipment includes a handy 3D Lidar scanner was used. The specification of the equipment is the GeoSLAM ZEB HORIZON Handheld 3D Scanner with a scanning speed of $300,000 \mathrm{pts} / \mathrm{sec}$ and a standard scanning range of 100 .

Since there is a limit to identifying tree species with Lidar equipment, the representative tree species of the compartment in the FMP record data were used to classify tree species.

\subsection{Methods}

GIS digital map joined with FMP documents and digital stock map was analysed and stratified. The number of sample points was allocated based on the area of forest stands. The total number of sample points is 283 , and 30 of these were used to compare the results of manual method and Lidar method.

By manual method we can write an inventory field book according to the traditionally known forest measurement method and calculate the total growing stock by substituting the biomass estimates provided by the National Institute of Forest Science based on tree specifications, height, and $\mathrm{DBH}$ (Diameter at breast height) [11].

The equation below shows how to convert forest biomass stock to carbon stock.

Biomass $=\mathrm{aDBH}^{b}$ Height $^{c}$

$C V_{p}=V_{p} \times B E F \times(1+R R) \times W D \times C F$

The equation for measuring biomass is estimated by the calculation with DBH and height as shown in (1). To estimate biomass, coefficients $a, b$ and c are needed [16], and each coefficients were provided from the National Institute of Forest Science in Korea depending on the tree species [11]. In the equation (2), $C V_{p}$ means p-year carbon accumulation of forest biomass in ground and underground parts. $V_{p}$ means 
p-year stem biomass stock. BEF is Biomass Expansion Factor. RR is Root-shoot Ratio. WD is Wood Density. CF is Conversion Factor. Its genuine value can be acquired from NiFoS. After acquiring carbon exchange coefficients, we can also estimate, present carbon weight of each forests. This method is described in detail by the Korea Forest Service and the Korea Forest Carbon Center as Forest Carbon Offset Scheme [14].

The FMP method is as follows. Baegunsan Mountain Research forest has been well equipped with forest management plans, so it is possible to see how much standing stock differs from year to year in each sub-compartment. Based on this, the current growing stock per hectare can be obtained.

Table 1. Different methods estimating growing stock

\begin{tabular}{|c|c|c|c|c|}
\hline & $\begin{array}{c}\text { plot } \\
\text { size }\end{array}$ & input & estimation & output \\
\hline $\begin{array}{c}\text { Method 1 } \\
\text { (manual) }\end{array}$ & $\begin{array}{c}20 \times 20 \\
\mathrm{~m}^{2}\end{array}$ & $\begin{array}{c}\text { DBH, } \\
\text { height, tree } \\
\text { species }\end{array}$ & $\begin{array}{c}\text { allometric } \\
\text { equation }\end{array}$ & $\begin{array}{c}\text { growing } \\
\text { stock }\end{array}$ \\
\hline $\begin{array}{c}\text { Method 2 } \\
\text { (Lidar) }\end{array}$ & $\begin{array}{c}20 \times 20 \\
\mathrm{~m}^{2}\end{array}$ & DBH, height & $\begin{array}{c}\text { allometric } \\
\text { equation }\end{array}$ & $\begin{array}{c}\text { growing } \\
\text { stock }\end{array}$ \\
\hline $\begin{array}{c}\text { Method 3 } \\
\text { (FMP) }\end{array}$ & $\begin{array}{c}20 \times 50 \\
\mathrm{~m}^{2}\end{array}$ & period & $\begin{array}{c}\text { annual } \\
\text { change }\end{array}$ & $\begin{array}{c}\text { growing } \\
\text { stock }\end{array}$ \\
\hline
\end{tabular}

In this research, $\mathrm{t}$-test was used to see if there was any difference in the results from the method 1 measured manually and the method 2 measured with terrestrial Lidar equipment.

\section{RESULTS AND DISCUSSION}

The following are the results of the study. First, a Lidar measurement was performed for 283 sample area, and each single tree was identified by image processing. The information of tree height and $\mathrm{DBH}$ were also extracted. Figure 1 shows a part of these images.

Paired t-test was applied to verify that there is a difference between the two methods of comparing the growing stock per ha obtained using method 1 and method 2 for the same sample area [17].

The null hypothesis $\left(H_{0}\right)$ is "there is no difference in the amount of growing stock per ha obtained by the two forest survey methods", and the alternative hypothesis $\left(H_{a}\right)$ is " there is difference in the amount of growing stock per ha". As a result of the paired sample test, the t statistic for the deviation of the two methods is 0.73 , which does not exceed the rejection value of $2.05(\mathrm{df}=29$, alpha $=0.05)$, so the null hypothesis $H_{0}$ cannot be rejected. That is, there is no difference between the two methods at $95 \%$ confidence levels.

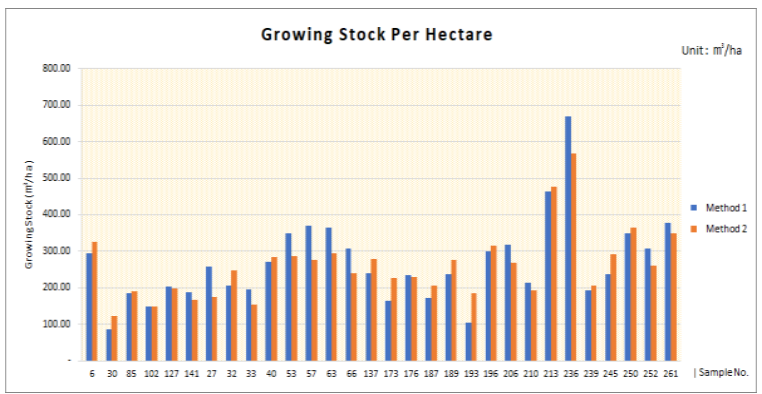

Figure 2. Result of t-test on the amount of growing stock per ha

In most cases, the result difference between methods is not significant, except in particular in cases where the gap between methods has widened significantly, such as sample no. 236. However, the overall sum shows that the Lidar method is somewhat lower than the manual method. This is considered to be an error due to the difficulty of accurately reflecting the characteristics of the object when using the Lidar method. In other words, shrubs and bushes, if they are large enough in diameter, are mistaken for trees and reflected in the calculation. Conversely, people need to intervene directly to reduce this error, and if the error caused by a person's work is large enough, the value obtained by Lidar may be small enough.

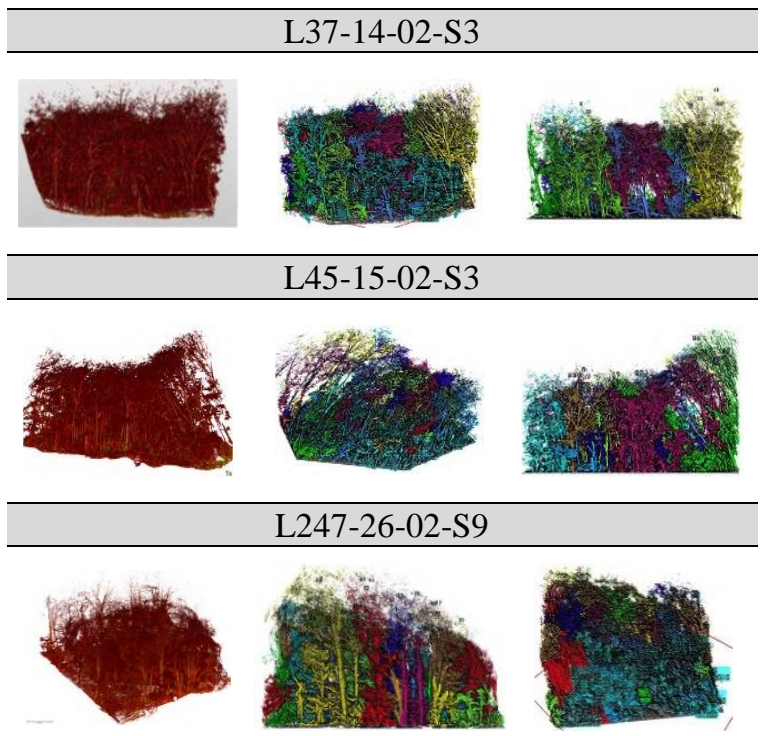

Figure 1. LiDAR measured image processing (sample no.37, 45, 247)

The following table 2 represents estimated stockper-ha by surveying 283 samples using terrestrial Lidar, classifying the sites of the Baegunsan Mountain by forest types. As a result of t-test, there is 
Table 2. Total carbon stock, growing stock per ha, and annual growth depending on tree species

\begin{tabular}{|c|c|c|c|c|c|c|c|}
\hline $\begin{array}{c}\text { Tree } \\
\text { species }\end{array}$ & $\begin{array}{l}\text { Rotation } \\
\text { age (yrs) }\end{array}$ & $\begin{array}{c}\text { Total } \\
\text { area (ha) }\end{array}$ & Sample & $\begin{array}{l}\text { Total carbon } \\
\text { stock }(\mathrm{tC})\end{array}$ & $\begin{array}{c}\text { Growing } \\
\text { stock per ha } \\
\left(\mathrm{m}^{3} / \mathrm{ha}\right)\end{array}$ & $\begin{array}{l}\text { Annual } \\
\text { growth } \\
\left(\mathrm{m}^{3} / \mathrm{ha} / \mathrm{yr}\right) \\
\end{array}$ & $\begin{array}{l}\text { Site } \\
\text { index }\end{array}$ \\
\hline $\begin{array}{l}\text { Japanese } \\
\text { black pine }\end{array}$ & 60 & 499.83 & 10 & 52214.5 & 221.99 & 1.18 & 10 \\
\hline $\begin{array}{c}\text { Oriental } \\
\text { oak }\end{array}$ & 60 & 1717.05 & 55 & 215815.3 & 197.39 & 1.22 & 12 \\
\hline Larch & 50 & 137.79 & 2 & 5964.9 & 111.3 & 3.30 & 16 \\
\hline Pitch pine & 30 & 560.52 & 11 & 38498.9 & 151.89 & 0.00 & 10 \\
\hline Oak tree & 60 & 57.15 & 2 & 4766.0 & 121.95 & 4.21 & 16 \\
\hline Pine tree & 60 & 712.39 & 39 & 47224.2 & 160.05 & 1.75 & 10 \\
\hline $\begin{array}{c}\text { Mongolian } \\
\text { oak }\end{array}$ & 60 & 661.42 & 86 & 90844.7 & 187.14 & 3.09 & 12 \\
\hline Nut pine & 60 & 124.13 & 1 & 6641.0 & 117.18 & 3.58 & 12 \\
\hline Queritron & 60 & 1575.63 & 40 & 201840.0 & 175.13 & 3.06 & 12 \\
\hline Retinispora & 60 & 18.92 & 1 & 1455.6 & 220.88 & 1.71 & 12 \\
\hline $\begin{array}{c}\text { Other } \\
\text { Conifer }\end{array}$ & 60 & 20.56 & 2 & 693.5 & 80.75 & 1.61 & 10 \\
\hline $\begin{array}{c}\text { Other } \\
\text { Broadleaf }\end{array}$ & 60 & 1883.24 & 34 & 214696.9 & 163.28 & 3.06 & 12 \\
\hline
\end{tabular}

no difference between manual measurement and Lidar measurement methods, so the entire forest of the target site could be obtained with only the Lidar measurement.

\section{CONCLUSION}

In this study, there is no difference between the traditional manual survey method and the method using Lidar equipment for measuring carbon absorption. However, when using Lidar, it is difficult to distinguish species, so there should be FMP information to supplement this.

\section{ACKNOWLEDGMENTS}

We would like to express special appreciation to National Information Society Agency (NIA) for support and assistance.

\section{REFERENCES}

[1] Ring, M. J., Lindner, D., Cross, E. F., \& Schlesinger, M. E. (2012). Causes of the global warming observed since the 19th century. Atmospheric and Climate Sciences, 2(04), 401. DOI: https://doi.org/10.4236/acs.2012.24035

[2] Paris agreement. In Report of the Conference of the Parties to the United Nations Framework
Convention on Climate Change (21st Session, 2015: Paris). Retrived December (Vol. 4, p. 2017).

[3] Schneider, L., \& La Hoz Theuer, S. (2019). Environmental integrity of international carbon market mechanisms under the Paris Agreement. Climate Policy, 19(3), 386-400. DOI: https://doi.org/10.1080/14693062.2018.1521332

[4] Brack, D. (2019, March). Background analytical study forests and climate change. In United Nations forum on forests (p. 3).

[5] Huang, L., Chen, K., \& Zhou, M. (2020). Climate change and carbon sink: a bibliometric analysis. Environmental Science and Pollution Research, 27(8), 8740-8758. DOI: https://doi.org/10.1007/s11356-019-07489-6

[6] Kim, Y. H., et al. (2013). Project Design Guidelines For Forest Carbon Offset, National Institute of Forest Science, Korea

[7] Korea Forest Service, "Forest Carbon Offset Scheme", 2015 [Brochure]

[8] Seo, S. H., et al. (2019). National Atlas of Korea. National Geographic Information Institute.

[9] Korea Forest Service, "Public Benefits of Korea Forest in 2018", 2020 
[10] Forest Carbon Center, "Forest Carbon Inventory Guidelines for Forest Carbon Offset Project (version 02)", 2017

[11] Kang, J. T., et al. (2018). Stumpage Volume, Biomass, and Stand Yield Table, National Institute of Forest Science, Korea

[12] Kim, Y. H. (2017). Analysis of Forest Carbon Offset Credits from Forest Management Project based on to the Korean Forest Carbon Offset Standard and the VCS Methodology-Case Study on the Methodology for Forest Management through Extension of Rotation Age. Journal of Climate Change Research, 8(4), 369-375. DOI: https://doi.org/10.15531/ksccr.2017.8.4.369

[13]SNU Research forest, "Forest Inventory Record", 2013

[14]SNU Research forest, "The 8th Forest Management Plan Manual”, 2013

[15] Korea Forest Service. (2008). Forests and forestry technology.

[16] Beets, P. N., Kimberley, M. O., Oliver, G. R., Pearce, S. H., Graham, J. D., \& Brandon, A. (2012). Allometric equations for estimating carbon stocks in natural forest in New Zealand. Forests, 3(3), 818-839. DOI: https://doi.org/10.3390/f3030818

[17]Ryu, K. K. (2013). Statistics (3rd edition). Beopmunsa, Korea. 